\title{
Isolation and Purification of $\beta$-Carotene from Morinda citrifolia as HPLC Standard and Active Pharmaceutical Ingredient
}

\author{
Rashidi Othman ${ }^{1, *}$, Fatimah Azzahra Mohd Zaifuddin ${ }^{2}$ and Norazian Mohd Hassan ${ }^{2}$ \\ ${ }^{1}$ International Institute for Halal Research and Training (INHART), Herbarium Unit, Department of Landscape \\ Architecture, Kulliyyah of Architecture and Environmental Design, International Islamic University Malaysia, \\ 53100 Kuala Lumpur, Malaysia \\ ${ }^{2}$ Department of Pharmaceutical Chemistry, Kulliyyah of Pharmacy, International Islamic University Malaysia, \\ 25200 Kuantan, Malaysia
}

\begin{abstract}
Qualitative and quantitative analysis of individual carotenoids content and composition are complicated, time consuming and in fact very costly. The crucial and vital part is the availability and reliability of the pure standards. Most of the individual carotenoids are commercially available either in natural or synthetic form but they are quite expensive and some of it not available in the market anymore. These problems strongly associated with the accuracy and reliability of High Performance Liquid Chromatography (HPLC) analysis data. Therefore, this study aimed to set up an analytical scheme of obtaining $\beta$-carotene standard from the leaves of Morinda citrifolia as one of the carotenoid standards for HPLC analysis. M. citrifolia has been selected due to its abundance throughout the year with tropical climate. The scheme via open column chromatography (OCC) established that the purity of $\beta$-carotene standard was $97 \%$ and the coefficient of correlation was 0.9923 . However after 30 day storage period of time, the purity decreased to $95.46 \%$. Although these had an effect on the carotenoid standard stability but it can be a reliable source of $\beta$-carotene standard for HPLC analysis as well as active pharmaceutical ingredient for cosmeceutical, nutraceutical, food and beverage industries.
\end{abstract}

Keywords: Carotenoid, $\beta$-carotene, Morinda citrifolia, Active pharmaceutical ingredient.

\section{INTRODUCTION}

Carotenoids are antioxidants with pharmaceutical potential. More than 600 carotenoid structures are known, but source material for their extraction is limited [1]. The basic skeleton of carotenoid structure consists of 40-carbon tetrapene derived from eight 5-carbon isoprenoid units that joined in linear and symmetrical order. These hydrocarbon carotenoids structure can be classified into carotenes or xanthophylls. Xanthophylls are those containing oxygen whereas those without oxygen groups are termed as carotenes. The most common oxygen functions are hydroxyl and epoxy groups, followed by aldehyde, keto, carboxy, carbomethoxy and methoxy groups. Hydrogenation, dehydrogenation, cyclization, desaturation, isomerization, hydroxylation, epoxidation and deepoxidation or combination of these processes determining the great diversity of carotenoid structures. Carotenoids may be acyclic (phytofluene, $\zeta$-carotene, lycopene), monocyclic $(\gamma$-carotene), or bicyclic ( $\beta$-carotene). Most of the carotenoids important in photosynthetic organisms are xanthophylls or oxygenated carotenoids [2]. Therefore, characterization and quantification of carotenoids

${ }^{*}$ Address of correspondence to this author at the International Institute for Halal Research and Training (INHART), Herbarium Unit, Department of Landscape Architecture, Kulliyyah of Architecture and Environmental Design, International Islamic University Malaysia, 53100 Kuala Lumpur, Malaysia; Tel: +6012 6644772; Fax: +603 61964864; E-mail: rashidi@iium.edu.my remains a very difficult task, expensive and complicated. Although several carotenoids preparations from either synthetic or natural sources such as lutein and lycopene have been performed, other pure acyclic, monocyclic or bicyclic carotenes have not been obtained and the characteristics of these reactions have not been established [3].

Operating the high performance liquid chromatography (HPLC) is indeed not cheap, especially in third world and developing countries. Besides, data accuracy and reliability in HPLC analysis depend solely on calibration of the instrument by using standards. For carotenoid analysis, only certain carotenoid standards are available commercially but they are expensive for which new researchers are not capable to buy all the standards needed to identify and quantify diversified carotenoids content in our food chain. Moreover, the standards are prone to isomerization and oxidation if they are not handled or transported properly [4]. The implication of this situation will make research and development in those countries stunted and abandoned. By establishing scheme of $\beta$ carotene from $M$. citrifolia which is abundance and available throughout the year in Malaysia it can be a reliable source of carotenoid standard for HPLC analysis. It is generally believed that third world countries and developing countries are much benefitted

(c) 2017 Lifescience Global 
from the outcome of this scheme due to budget constraint and lack of supplies as it is cheap and commonly available throughout the year

\section{MATERIALS AND METHODS}

\section{Isolation of $\beta$-Carotene Standard by Open Column Chromatography}

Morinda citrofolia (noni or mengkudu) was used for isolation of $\beta$-carotene standard by open column chromatography (OCC) as described further by [2]. Approximately $200-250 \mathrm{~g}$ of leaves were freeze-dried for 72 hours, after which the samples were ground into fine powder and kept at $-20^{\circ} \mathrm{C}$ until further analysis.

\section{Extraction of Carotenoids}

The extraction procedure essentially follows the methods described by Othman [2] and Fatimah et al. [5]. $5.0 \mathrm{~g}$ of powdered sample was rehydrated with distilled water and extracted with a mixture of acetone and methanol (7:3) at room temperature until colorless. The crude extracted was then centrifuged for $5 \mathrm{~min}$ at $10000 \mathrm{~g}$ and stored at $4^{\circ} \mathrm{C}$ in the dark prior to analysis.

\section{Partition to Petroleum Ether}

To transfer carotenoids from acetone to petroleum ether, $100 \mathrm{ml}$ of petroleum ether was placed in a 500 $\mathrm{ml}$ separator funnel. A small portion $(50 \mathrm{ml})$ of the acetone extract was added and then $300 \mathrm{ml}$ of distilled water was added slowly to the combined supernatants. The solution was then allowed to separate and the lower aqueous-acetone layer was discarded. This operation was repeated until all of the extract has been transferred to petroleum ether. The petroleum ether extracts were then washed five times with $200 \mathrm{ml}$ distilled water to remove residual acetone. Then the carotenoid solutions in petroleum ether were concentrated until approximately $10 \mathrm{ml}$ remained.

\section{Preparation of the Column}

The chromatography procedures were adapted from Rodriguez-Amaya and Kimura [6] and Othman [2]. The adsorbent used was magnesium oxide-hyflosupercel (MgO-HS) in 1:1 ratio, which has been activated at 110 ${ }^{\circ} \mathrm{C}$ for two hours and left to cool down for few hours. The adsorbent bed was tightly packed into the column with the assistance of vacuum pump, and an ample layer of sodium sulphate anhydrous was packed on top of the adsorbent bed. The column was re-equilibrated with one bed of petroleum ether until the solvent surface was just above the sodium sulphate layer. The size of chromatographic column used in this study was of $300 \mathrm{~mm}$ length with $10 \mathrm{~mm}$ nominal bore. The top of the column was maintained with a cover of petroleum ether until the chromatography process was completed.

\section{Developing the Column}

The MgO:Hyflosupercel (1:1) column was developed starting with $1 \%$ and $8 \%$ petroleum ether, followed by $2 \%, 5 \%, 10 \%, 15 \%, 20 \%$ up to $70 \%$ of acetone in petroleum ether. The eluted fraction collected from OCC was then washed with distilled water. To verify the purity of the standard an aliquot from the isolate was taken and verified through HPLC by checking the chromatogram profile obtained with a photodiode array detector.

\section{HPLC Analysis}

The analysis for the eluted fraction collected from OCC was performed on an Agilent model 1200 series in accordance to Othman [2]. The column used was a ZORBAX SB- $\mathrm{C}_{18}$ end capped $5 \mu \mathrm{m}, 4.6 \times 250 \mathrm{~mm}$ reverse phase column (Agilent Technologies, USA). The eluents used were $(A)$ acetonitrile:water $(9: 1 \mathrm{v} / \mathrm{v})$ and (B) ethyl acetate. The column separation was allowed via a series of gradient at a flow rate of $1.0 \mathrm{~mL}$ min-1. The column would be allowed to re-equilibrate in $100 \% \mathrm{~A}$ for $10 \mathrm{~min}$ prior to the next injection. Throughout the analysis, temperature of the column was maintained at $20^{\circ} \mathrm{C}$ while the injection volume was $10 \mu \mathrm{L}$ each. Detection was at the wavelengths of maximum absorption of the carotenoids in the mobile phase (max plot): neoxanthin $438 \mathrm{~nm}$; violaxanthin 441 $\mathrm{nm}$; lutein $447 \mathrm{~nm}$; zeaxanthin $452 \mathrm{~nm}$ and $\beta$-carotene $454 \mathrm{~nm}$. Carotenoids from the extracts were identified by co-chromatography with standards and by elucidation of their spectral characteristics using a photo-diode array detector. For the standard curves, triplicate aliquots of 1, 2, 3, 4 and $5 \mathrm{ml}$ were transferred to culture tubes, dried under oxygen-free nitrogen, and just before injection, dissolved in $1 \mathrm{ml}$ HPLC grade ethyl acetate and filtered through a $0.22 \mu \mathrm{m}$ PTFE syringe filter (Millipore) and $10 \mu \mathrm{l}$ was analysed by HPLC. Curves constructed with five different concentrations for each carotenoid, in triplicate, were confirmed as linear with a correlation coefficient $\geq 0.95$.

\section{RESULTS AND DISCUSSION}

For this experiment, $M$. citrifolia leaves have been randomly selected to be chromatographed to obtain $\beta$ carotene standard. Production of $\beta$-carotene standard from M. citrifolia leaves would be an advantage since it 


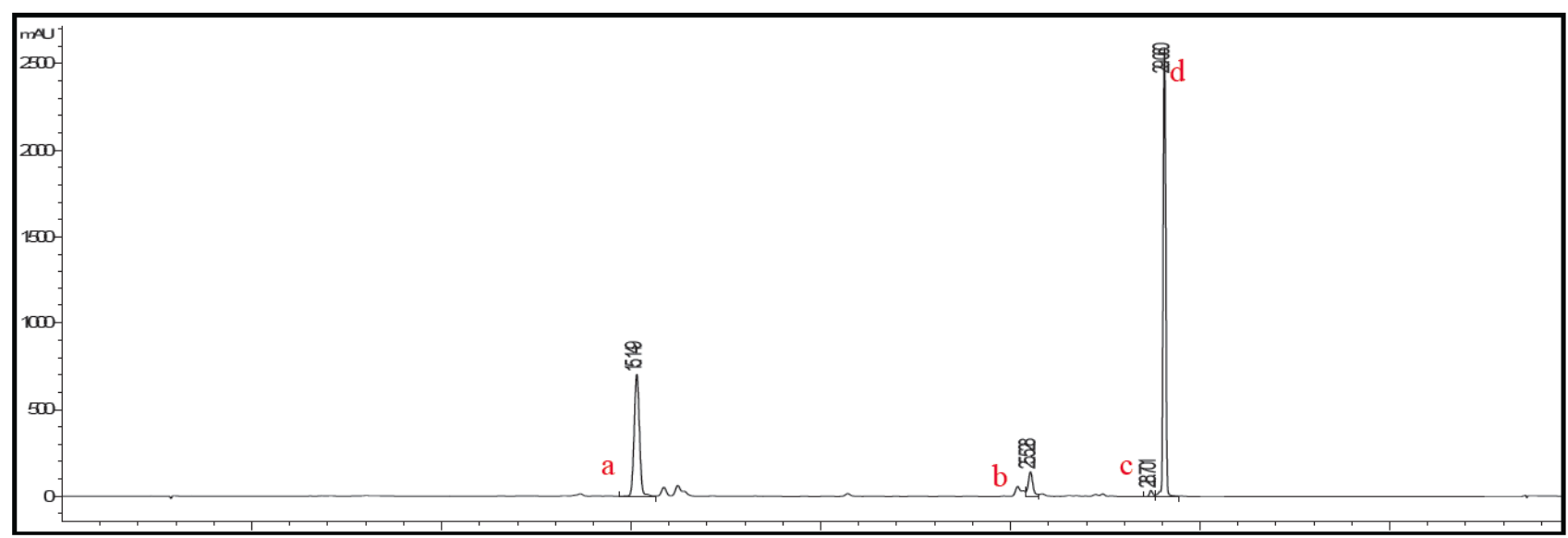

Figure 1: HPLC separation of carotenoids in M. citrifolia leaves: (a) lutein, (b) $\beta$-cryptoxanthin (c) $\alpha$-carotene and (d) $\beta$-carotene.

is economically effective because the leaves are available all-year round and remain underutilized other than being a source of traditional vegetable (ulam) in daily diets among the Malay community [7]. Besides, people nowadays are more interested in the fruits of $M$. citrifolia for commercial production of supplementary juices. The extract of $M$. citrifolia leaves was analysed for its carotenoids profiling and through HPLC analysis, there are four types of known carotenoids were detected: lutein, $\beta$-cryptoxanthin, $\alpha$-carotene and $\beta$ carotene at retention time of $15.1,25.5,28.7$ and 29.1 minutes respectively (as shown in Figure 1). Previous determination of carotenoids in $M$. citrifolia has shown that this plant species contains lutein and $\beta$-carotene only [8] but with additional two more xanthophylls (neoxanthin and violaxanthin) in our previous work [5]. These differences are highly influenced by several internal and external factors such as genotypes, level of maturity, nutritional supply, light intensity, temperature, geological and geographical aspects, preand postharvest handling or processing as well as the effect of pesticides [9-16].

Although HPLC has been such a highly reliable instrument used in food carotenoid analysis nowadays, another widely used technical approach in this particular field is separation through OCC $[17,18]$. The application of OCC offers rather convenient since there is no critical requirement of a continuous supply of carotenoid standards and the eluted fractions can be directly quantified by using UV-Vis spectrophotometry. This could be possibly done with the use of published coefficients of absorption for the respective compounds [19]. However, the use of OCC for isolating carotenoids has its own disadvantages too. For example, some of the xanthophylls can be possibly eluted in the same fraction and thus need to be further purified in order to obtain a highly pure standard [19]. [19] also added that
OCC is a technique which largely dependent on the analysts' handling skills and uses larger volume of samples and eluents. Through spectral characteristic elucidated by HPLC analysis, the first eluted fraction was identified to contain $\beta$-carotene with purity of $97.221 \%$. The purity is calculated by subtracting area covered by the peaks of impurities from the total area determined in the analysis, as follows:

Purity $(\%)=\left[\frac{\text { Peak area of } \alpha-\text { carotene }}{\text { Total peak area of } \alpha \text { - carotene }+ \text { impurities }}\right] \times 100 \%$

To investigate the stability of our isolated $\beta$ carotene, a test was held for a period of one month where the purity of the standard was observed at every 15 days. Under the storage condition applied in this study, it has been found that there is gradual reduction in terms of purity of the isolated $\beta$-carotene over time: $97.221 \%$ at day $0,96.161 \%$ at day 15 and $95.460 \%$ at day 30 . This reduced purity may be implied that there was degradation or isomerization of the carotenoid occurred during storage. Thus because, the carotenoids are such sensitive compounds to react with their surrounding due to high content of unsaturated bonds in their structures [20]. At the end period of stability analysis in 30 days, the remaining balance of $\beta$-carotene was dried down under gentle stream of nitrogen free oxygen gas, re-suspended in ethyl acetate and prepared as a stock standard solution. A multi-point calibration curve was constructed at the concentration of $0,0.2,0.4,0.6,0.8$ and $1.0 \mu \mathrm{g} / \mu \mathrm{L}$ respectively. As a result, a straight line curve obtained with $99.23 \%$ regression showing a well-defined curve as depicted in Figure 3 below. The working scheme established here was done in a period of 30 days before the isolated $\beta$-carotene can be used for quantification of this particular carotenoid in food composition studies. This period is however totally 

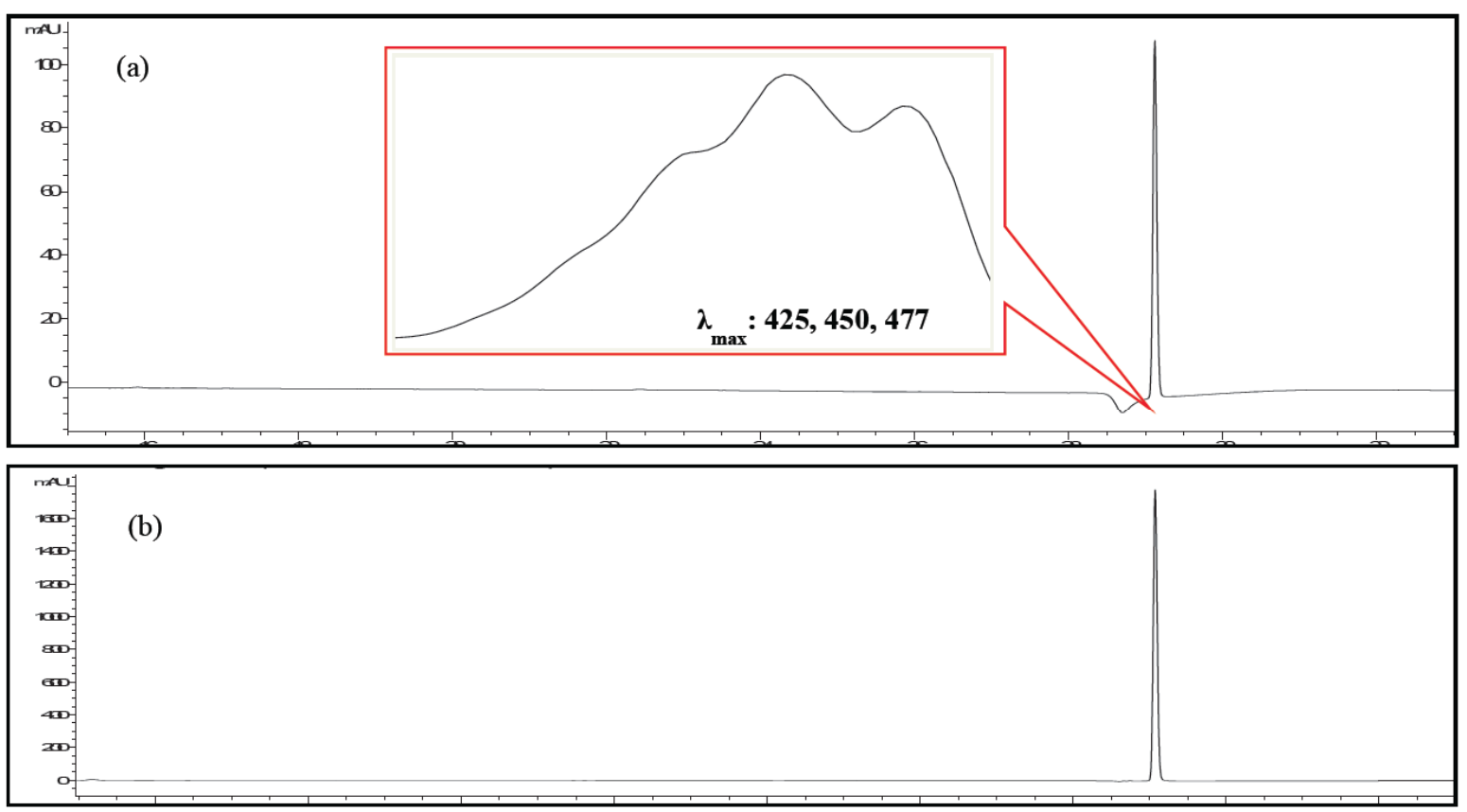

Figure 2: HPLC determination of $\beta$-carotene in (a) Sigma standard and (b) $M$. citrifolia at retention time of 29.1 minutes.

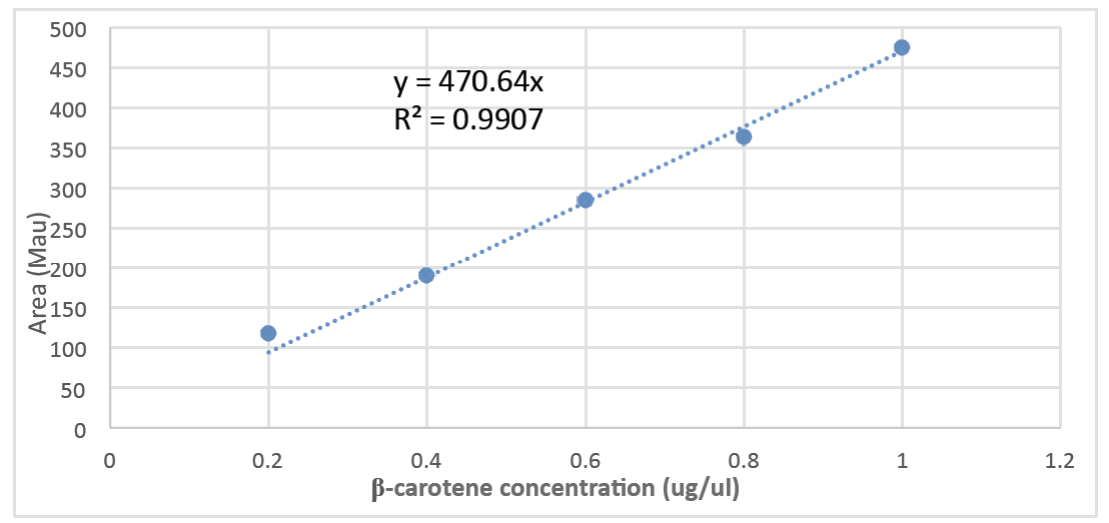

Figure 3: Calibration curve of the isolated $\beta$-carotene.

dependent on the handling skills and motivation of respective analysts. Due to the vulnerability of carotenoid towards oxidation and isomerization [20], therefore it is suggested that the isolated a-carotene standard is handled under subdues light and stored in amber containers flushed with nitrogen free oxygen gas within lowest temperature as possible.

\section{CONCLUSIONS}

The working scheme established here demonstrated that isolation of the $\beta$-carotene standard was successful with $95-97 \%$ pure at significantly lower cost and lesser time of production. This method also secures uninterrupted carotenoid analysis since researchers could maintain the availability of the respective standard in their laboratory. Further studies need to be taken to find an optimum storage condition to preserve the high quality of the standard and to prevent carotenoid degradation or isomerization during storage and transportation.

\section{ACKNOWLEDGEMENT}

This work was supported by Ministry of Higher Education (MOHE) and International Islamic University Malaysia (IIUM) under Research Grant RIGS16-3960560

\section{REFERENCES}

[1] Johnson EA, Schroeder WA. Advances in Biochemical Engineering and Biotechnology. Springer, Berlin 1996.

[2] Othman R. Biochemistry and genetics of carotenoid composition in potato tubers. Lincoln University, Christchurch, New Zealand, PhD thesis 2009.

[3] Britton G. Carotenoids Chemistry and Biology. Springer, New York 1989. 
[4] Norshazila S, Irwandi J, Rashidi O, Yumi Zuhanis $\mathrm{HH}$. Scheme of obtaining $\beta$-carotene standard from pumpkin (Cucurbita moschata) flesh. Int Food Res J 2012; 19: 531535.

[5] Fatimah AMZ, Norazian MH, Rashidi O. Identification of carotenoid composition in selected 'ulam' or traditional vegetables of Malaysia. Int Food Res J 2012; 19: 527-530.

[6] Rodriguez-Amaya D, Kimura M. HarvestPlus handbook for carotenoid analysis. HarvestPlus, Washington DC 2004.

[7] Saidin I. Sayuran tradisional, ulam dan penyedap rasa. Penerbit Universiti Kebangsaan Malaysia, Bangi, Malaysia 2000.

[8] Tee ES, Lim CL. Carotenoids composition and content of Malaysian vegetables and fruits by the AOAC and HPLC methods. Food Chem 1991; 41: 309-339. https://doi.org/10.1016/0308-8146(91)90057-U

[9] Rouchaud J, Moons C, Meyer JA. Effects of pesticide treatments on the carotenoid pigments of lettuce. J Agric Food Chem 1984; 32: 1241-1245. https://doi.org/10.1021/jf00126a008

[10] Lee JJ, Crosby KM, Pike LM, Yoo KS, Leskovar DI. Impact of genetic and environmental variation on development of flavonoids and carotenoids in pepper (Capsicum spp.). Sci Hort 2005; 106: 341-352. https://doi.org/10.1016/j.scienta.2005.04.008

[11] Schreiner M, Huyskens-Keil S. Phytochemicals in fruit and vegetables: Health promotion and postharvest elicitors. Crit Rev in Plant Sci 2006; 25: 267-278. https://doi.org/10.1080/07352680600671661

[12] Solovchenko AE, Avertcheva OV, Merzlyak MN. Elevated sunlight promotes ripening-associated pigment changes in apple fruit. Postharvest Biol Technol 2006; 40: 183-189. https://doi.org/10.1016/j.postharvbio.2006.01.013

[13] Lefsrud M, Kopsell D, Wenzel A, Sheehan J. Changes in kale (Brassica oleracea L. var. acephala) carotenoid and chlorophyll pigment concentrations during leaf ontogeny. Sci Hort 2007; 112: 136-141.

https://doi.org/10.1016/j.scienta.2006.12.026

[14] Aherne SA, Jiwan MA, Daly T, O'Brien NM. Geographical location has greater impact on carotenoid content and bioaccessibility from tomatoes than variety. Plant Foods Hum Nutr 2009; 64: 250-256.

https://doi.org/10.1007/s11130-009-0136-x

[15] Xu JG, Hu QP, Wang XD, Luo JY, Liu Y, Tian CR. Changes in the main nutrients, phytochemicals, and antioxidant activity in yellow corn grain during maturation. J Agric Food Chem 2010; 58: 5751-5756. https://doi.org/10.1021/jf100364k

[16] Yang J, Zhu Z, Wang Z, Zhu B. Effects of storage temperature on the contents of carotenoids and glucosinolates in Pakchoi (Brassica rapa L. ssp. Chinensis Var. Communis). J Food Biochem 2010; 34: 1186-1204. https://doi.org/10.1111/j.1745-4514.2010.00358.x

[17] Adewusi SRA, Bradbury JH. Carotenoids in cassava: Comparison of open-column and HPLC methods of analysis. J Sci Food Agr 1993; 62: 375-383. https://doi.org/10.1002/jsfa.2740620411

[18] Carvalho PRN, Collins CH, Rodriguez-Amaya DB. Comparison of provitaminA determination by normal-phase gravity- flow column chromatography and reversed-phase high performance liquid chromatography. Chromatographia 1993; 33: 133-137. https://doi.org/10.1007/BF02275893

[19] Kimura M. Rodriguez-Amaya D. A scheme for obtaining standards and HPLC quantification of leafy vegetable carotenoids. Food Chem 2002; 78: 389-398. https://doi.org/10.1016/S0308-8146(02)00203-0

[20] Britton G. Structure and properties of carotenoids in relation to function. FASEB J 1995; 9: 1551-1558. 